\title{
LETTER
}

\section{Echographic evaluation of ICU patients with tissue Doppler imaging: more studies and more consensus are still needed}

\author{
Jérôme Fichet*, Benjamin Sztrymf and Frédéric M Jacobs \\ See related research by Moschietto et al., http://ccforum.com/content/16/3/R81, and related research by Weng et al., \\ http://ccforum.com/content/16/3/R71
}

In many intensive care units (ICUs), cardiac transthoracic echocardiography (TTE) has replaced invasive monitoring in routine evaluation of acutely ill patients. Since the mid '80s, there have been many studies of ICU patients, most of whom were receiving mechanical ventilation (MV). With the emergence of new TTE modalities such as tissue Doppler imaging (TDI) and strain rate or threedimensional imaging, new studies are currently available. TDI is now widely used in cardiology and is a powerful tool in the assessment of left ventricular filling pressures (LVFPs), relaxation, or right ventricular function. It was suggested that the ratio of pulsed Doppler mitral flow in early diastole (E wave) over early diastolic mitral annulus velocity ( $E_{a}$ with TDI), known as $E / E_{a}$, was closely related to LVFP. However, in many clinical situations, a lack of correlation between $\mathrm{E} / \mathrm{E}_{\mathrm{a}}$ and LVFP was observed, even in patients with spontaneous breathing [1]. Three studies focusing on TDI and left ventricular function in ICU patients were recently published [2-4], two of them in Critical Care $[2,4]$. These studies provide new approaches in the assessment of systolic or diastolic function during septic shock and weaning from MV. In all studies, patients were mechanically ventilated, adding complexity to the TTE examination. For years, invasive pressure measurements in patients under MV have been performed at the end-expiratory time, when intra-thoracic pressure is closer to atmospheric pressure in most cases. For TTE study, things are slightly different. Doppler study (such as E wave) aims to determine direction and velocity of blood flow. That flow, as intra-cardiac pressure, depends of the respiratory cycle. By contrast, TDI determines the velocity of the myocardium and is considered relatively load-independent. So the necessity to perform

*Correspondence: jerome.fichet@abc.aphp.fr

Service de Réanimation médicale polyvalente, Hôpital Antoine Béclère et Hôpitaux universitaires Paris-Sud, 157 rue de la porte de Trivaux, 92141 Clamart, France measurements $\left(\mathrm{E}_{\mathrm{a}}\right)$ at a certain time of the respiratory cycle may be questioned. Moreover, methodological differences between studies may be confusing (Table 1). These differences may lead to a loss of information in some cases and eventually may explain the differences observed between TTE and invasive monitoring. At the bedside, the clinician may be tempted to use a simple beat measurement and disregard the respiratory time. Further studies focusing on the feasibility and influence of MV on TDI parameters are needed [5]. Guidelines regarding the methods and designs of future trials in the ICU will be valuable, as these studies demonstrate that a quantitative assessment of cardiovascular parameters over a simple qualitative approach is possible with TTE in patients on MV. As in the study by Moschietto and colleagues [2], evolution of these values may provide crucial information for the clinician.

\section{Abbreviations \\ $E / E_{a^{\prime}}$ pulsed Doppler mitral flow in early diastole/early diastolic mitral annulus velocity; ICU, intensive care unit; LVFP, left ventricular filling pressure; MV, mechanical ventilation; TDI, tissue Doppler imaging; TTE, transthoracic echocardiography.}

\section{Competing interests}

The authors declare that they have no competing interests.

Published: 26 June 2012

\section{References}

1. Mullens W, Borowski AG, Curtin RJ, Thomas JD, Tang WH: Tissue Doppler imaging in the estimation of intracardiac filling pressure in decompensated patients with advanced systolic heart failure. Circulation 2009, 119:62-70

2. Moschietto S, Doyen D, Grech L, Dellamonica J, Hyvernat H, Bernardin G: Transthoracic Echocardiography with Doppler Tissue Imaging predicts weaning failure from mechanical ventilation: evolution of the left ventricle relaxation rate during a spontaneous breathing trial is the key factor in weaning outcome. Crit Care 2012, 16:R81.

3. Landesberg G, Gilon D, Meroz Y, Georgieva M, Levin PD, Goodman S, Avidan $A$, Beeri R, Weissman C, Jaffe AS, Sprung CL: Diastolic dysfunction and mortality in severe sepsis and septic shock. Eur Heart J 2012, 33:895-903.

4. Weng L, Liu YT, Du B, Zhou JF, Guo XX, Peng JM, Hu XY, Zhang SY, Fang Q, Zhu $W L$ : The prognostic value of left ventricular systolic function measured by tissue Doppler imaging in septic shock. Crit Care 2012, 16:R71. 
Table 1. Methodological differences among recent studies

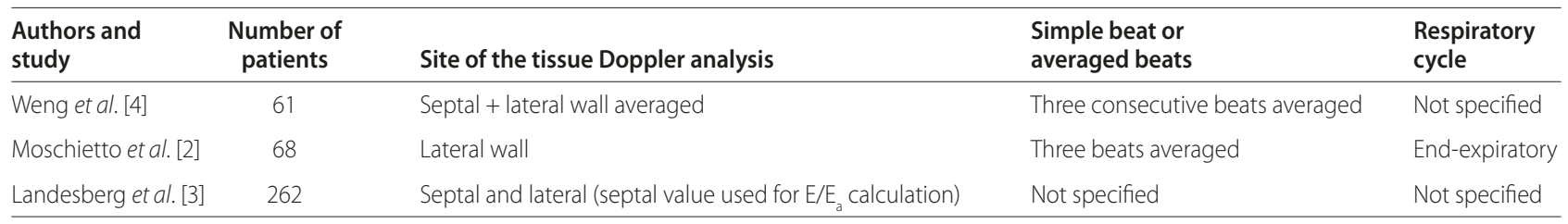

$\mathrm{E} \mathrm{E}_{\mathrm{a}^{\prime}}$ pulsed Doppler mitral flow in early diastole/early diastolic mitral annulus velocity.

5. Fichet J, Moreau L, Genée O, Legras A, Mercier E, Garot D, Dequin PF, Perrotin $D$ : Feasibility of right ventricular longitudinal systolic function evaluation with transthoracic echocardiographic indices derived from tricuspid annular motion: a preliminary study in acute respiratory distress syndrome. Echocardiography 2012, 5:513-521. doi:10.1186/cc11377

Cite this article as: Fichet J, et al.: Echographic evaluation of ICU patients with tissue Doppler imaging: more studies and more consensus are still needed. Critical Care 2012, 16:433. 